\title{
Policy Modeling Under Fixed and Flexible Price Regimes: SAM-CGE Transitional Applications to Poland and Hungary
}

M. C. Braber, S. I. Cohen, Erasmus University, Rotterdam, The Netherlands

T. Révész, Budapest University of Economic Sciences, Hungary

Z. Zólkiewski, Central Statistical Office, Warsaw, Poland

\section{INTRODUCTION}

The proper approach to the transformation of the planningoriented economies to market-oriented economies is a very controversial subject. Some economists have used the term "shock therapy" to emphasize the necessity of a change in mentality among consumers and producers. Others advocate a "gradual" approach to economic restructuring. Some support a combination of the two approaches. There are momentarily no operational frameworks that are able to appraise such choices against each other, or are able to monitor the actual results of any choice made. This is rendered most difficult in situations of hectic price changes and unstable relations that preclude the possibility of a reliable aggregation of data and empirical modeling during transition.

Less ambitious, but nevertheless helpful in reflecting on performance aspects of the transformation process, is a comparative static analysis based on social accounting matrices, SAM, and computable general equilibrium models, CGE. The SAM can be seen as

Address correspondence to Prof. Solomon Cohen, Department of Economic Sciences, Erasmus Universiteit Rotterdam, Postbus 1738, 3000 DR Rotterdam, The Netherlands.

The authors would like to thank Adam Czyzewski, Harry de Haan, Fred Lafeber and Ernö Zalai for useful feedback. The work was supported by a grant from the European Commission.

Received March 1995; final draft accepted September 1995. 
a baseline measurement of the general equilibrium interactions in the economy for a particular year. With a minimum of manipulations the SAM is convertable to either a fixed-price or flexible-price model (cf. Cohen, 1989; Pyatt, 1991, and Dervis, de Melo, and Robinson, 1982; Piggott and Walley, 1985). These two versions are very handy in replicating a centrally planned and a free-market situation, respectively. By running one and the same policy injection in both versions, it is possible to detect the signs, sizes, and locations of the discrepancies. Furthermore, by applying sensitivity analysis, one can appraise under which structural changes the discrepancies can be more effectively resolved.

The SAM displays the transactions of the economy with regard to receipts and expenditures of production activities, factors, and institutions (whether households, firms, government, or rest of the world) in a matrix form. Because of its algebraic properties, the SAM can be viewed as a model of the economy. It can be broken down in an endogenous and an exogenous part; the latter can be recalculated as a matrix of proportional coefficients in terms of column totals, which can then be inverted to give multipliers that show the impacts of changes in the exogenous part on sectoral output, household incomes, and so forth.

The impact multipliers in a fixed-price SAM model assume relative prices unchanged so that all impacts go into quantity changes. As such this version of the SAM can be seen to represent a truly centrally planned economy in which prices are fixed by the state and quantities carry the burden of the adjustment. The impact multipliers of an imposed injection, to be fully realized in quantity changes, assume the availability of sufficient production capacity. Especially of relevance in this context is the relative size of the injection to the available capacity.

On the other hand, a free-market economy is commonly modeled as a computable general equilibrium model. As is well known, the rules of the game in a CGE model are different from those in a fixed-price SAM model. In the CGE model producers maximize their profits and consumers maximize their utility in markets in which the demand for and supply of products and factors are cleared at flexible equilibrium prices. Because the SAM for a particular year can be seen as a baseline measurement of the general equilibrium interactions in the economy, the matrix can serve as a modular framework for replicating a free-market situation with endogenous prices. We aim in the second formulation to switch 
the regime towards a CGE model. The same policy simulation applied to the fixed-price SAM model can be now inserted in the flexible-price CGE model to give alternative results.

The SAM-CGE can be seen as the opposite poles between the central planning model and free-market model. In this paper, we review applicability of SAM-CGE to the modeling of economies in transition from a pure Centrally Planned Economy (CPE) to a pure Free-Market Economy (FME). Two countries serve as case studies: Poland and Hungary.

The paper is structured as follows: In the next section the fixedprice SAM model and its applicability to centrally planned economies will be discussed. In Section 3 the CGE model will be presented. Two demonstrative simulations are performed with both models for two different countries - Poland and Hungary - for two different base periods. The simulation results for the Polish economy will be examined in Section 4; the Hungarian results will be reviewed in Section 5. Finally, in Section 6, a summary and some concluding remarks will be given.

\section{THE FIXED-PRICE SAM MODEL}

The SAM multiplier model is a linear model of the form:

$$
y=M x
$$

where:

$$
\begin{aligned}
M=(I-S)^{-1} & =\text { multiplier matrix } \\
S & =\text { matrix of average expenditure } \\
& \text { propensities for endogenous accounts, } \\
y & =\text { endogenous variables } \\
x & =\text { exogenous variables }
\end{aligned}
$$

Endogenous variables represent SAM totals to be explained by the model, while exogenous variables are aggregate injections into the endogenous part of the economy. The distinction between endogenous and exogenous parts of the economy (respectively, accounts of SAM) should reflect behavioral features of the economy and the objectives of modeler. To be consistent with the specification of the CGE model presented in the next section, the accounts of social security, government, and the rest of the world are considered exogenous here. The procedure of transforming the SAM into a multiplier model has been presented in literature many times and will not be discussed here in detail. 
Formally, the fixed-price SAM model closely resembles the Leontief input-output model, LM, which is well-anchored in the planning procedures of the former Soviet Union. In that sense, the LM is a mathematical formulation of the so-called "material balances" planning technique widely used in CPEs. The basic assumptions behind the LM can be formulated as follows:

1. planners aim at achieving consistency between resources and uses, ${ }^{1}$

2. planners know all the relevant technological coefficients,

3. all technologies are characterized by fixed input proportions and constant returns to scale,

4. primary resources (capital stock, labor force) are outside the model,

5. prices are fixed.

The LM simulates a planning procedure in which planners fix net output targets (consumption, investments, exports) and then determine gross outputs and intermediate inputs necessary for achieving those targets. Thus, mutually consistent figures of net output (exogenous), gross outputs, and intersectoral deliveries form the production plan obtained by the LM. Because primary resources are not explicitly dealt with in the model, one should assume that planners are able to adjust production capacities to the requirements of the plan. This is consistent with the highly centralized nature of investment processes in CPEs on the one hand and with relatively large labor resources during the industrialization phase of the $1950 \mathrm{~s}$ and 1960 s on the other hand. ${ }^{2}$ As mentioned above, it is assumed as well that reallocation of resources does not change prices. This reflects the minor economic function of prices in CPEs where prices are under the control of planners and are kept relatively isolated from supply/demand and efficiency considerations.

The arguments for considering the LM and the fixed-price SAM model as simple models of a CPE lie in Assumptions 1-2 listed above. What differs in both models is the extension of the production relationships typical of the Leontief model to cover the full circular flow of the economy, typical of the SAM. In the SAM the central planner takes into account primary incomes generation,

\footnotetext{
'The other way to think of modeling planners' behavior is to assume that they optimize some social welfare function. The extensive discussion of different modeling approaches to central planning can be found in Bennett (1989).

${ }^{2}$ This interpretation refers rather to early stages of CPEs.
} 
their distribution and then redistribution among institutions, and finally its uses for consumption and savings purposes. The SAM applications for Poland and Hungary relate to the years 1987/88 and 1990, just before and somewhat halfway into the transition. The benchmark SAMs for these years are adapted versions of the SAMs compiled and published in Cohen (1993). ${ }^{3}$

\section{THE FLEXIBLE-PRICE CGE MODEL}

The CGE model applied in this paper portrays an idealized freemarket economy, which corresponds otherwise with the same disclusions of the constructed SAMs for Poland and Hungary. All markets distinguished in the model, namely, five goods markets, the labor market, and the market for foreign exhange, are fully competitive. Demand and supply are equalized at all markets by instantaneous adjustment of all prices.

Next to production activities the model distinguishes five types of actors: firms, households, social security, public sector, and rest of the world. Activities supply and demand goods and services and such factors as labor and capital. ${ }^{4}$ The producing firms maximize profits subject to a technological production constraint, taking all prices as given. Households are suppliers of labor and capital and are demanders for goods and services. They maximize utility subject to their budget constraint, again taking all prices as given. The social security agency is a passive body that accumulates and transfers funds. The public sector levies taxes and premiums, and it redistributes income over households. The public sector is also a demander and supplier of goods and services. The rest of the world is engaged in trade and financial transfers with the domestic economy.

The equilibrium described by the model is of a static nature without intertemporal effects. The equilibrium solutions can be altered by the government through changes in its expenditures and tax rates.

The flexible-price CGE model we use in this paper will apply the following notational conventions: Real variables are represented by lower-case characters. All price variables are represented by a

\footnotetext{
${ }^{3} \mathrm{~A}$ full explanation of the original SAM and its multiplier properties can be found in Cohen (1993).

${ }^{4}$ Because part of the intermediate inputs are imported, this demand implicitly generates a demand for foreign exchange.
} 
capital $P$ and a subscript identifying the corresponding real variables. Nominal variables are represented by capitals. Greek characters stand for parameters and coefficients. Activities are indicated by the subscripts $i$ and $j$; want categories by $k$. Households (and firms), social security, government, rest of the world are indicated by $h, s, g$, and $f$, respectively. Dollar signs denote variables expressed in foreign currency. Exogenous variables are denoted by overbars. The complete model is specified as follows.

Real output is determined from a two-level production structure. At the lowest level, sectoral real value-added $v_{i}$ is derived by a CobbDouglas function from labor $l_{i}$ and capital $k_{i}$; therefore smooth substitution possibilities exist at this level. The sectoral amount of capital is assumed to be fixed in the short run.

$$
v_{i}=\bar{v}_{i 0} * l^{\beta i *} \bar{k}_{i}^{1-\beta i}
$$

At the highest level real value-added is combined in fixed proportions with domestic and imported intermediate inputs to arrive at real output.

$$
x_{i}=\frac{v_{i}}{1-\Sigma_{j} \alpha_{j i}-\mu_{i}}
$$

By definition nominal output is equal to real output times the output price.

$$
X_{i}=P_{x_{i}}^{*} x_{i}
$$

Value-added prices $P_{v i}$ can be derived by deducting indirect tax rates $\sigma_{i}$ and unit costs of intermediate inputs from output prices. Imported intermediate goods are valued at exogenously fixed foreign prices $P_{m i}^{\$}$, which are transformed into domestic currency by multiplying with the exchange rate $E R$.

$$
P_{v_{i}}=\left(1-\sigma_{i}\right) * P_{x_{i}}-\sum_{j} \alpha_{j i} * P_{x_{j}}-\mu_{i} * E R * \bar{P}_{m_{i}}^{\phi_{i}}
$$

Each sector is assumed to consist of many similar firms that all maximize profits in perfectly competitive product and labor markets. The latter implies that wage and prices are given for the individual firm, and this allows us to treat each sector as one large price-taking firm. Following first-order conditions for profit maximization, firms will hire labor $l_{i}$ until the wage rate $P_{l}$ equals the value of its marginal product.

$$
P_{l}^{*} l_{i}=\beta_{i}^{*} P_{v_{i}}^{*} x_{i}
$$


The remuneration of capital is the residual nominal value-added after labor is paid its share. Because the volume of capital is fixed, remuneration rates $\boldsymbol{P}_{k i}$ have to adjust to be equal to the value of marginal product of capital. Consequently, remuneration rates of capital may differ among sectors.

$$
P_{k_{i}} * \bar{k}_{i}=\left(1-\beta_{i}\right) * P_{v_{i}}^{*} x_{i}
$$

Total demand for labor is equal to the exogenous supply. The wage rate is solved from this equilibrium equation.

$$
\sum_{i} l_{i}=\bar{l}
$$

Primary income of institutions $Y^{p}$ consists of factor remunerations, which are distributed in fixed proportions. Primary income of government comprises also indirect taxes.

$$
\begin{aligned}
& Y_{h}^{p}=\omega_{h} * P_{l} * \bar{l}+\pi_{h} * \sum_{i} P_{k_{i}} * \bar{k}_{i} \\
& Y_{s}^{p}=\omega_{s} * P_{l} * \bar{l}+\pi_{s} * \sum_{i} P_{k_{i}} * \bar{k}_{i} \\
& Y_{g}^{p}=\omega_{g} * P_{l}^{*} \bar{l}+\pi_{g} * \sum_{i} P_{k_{i}} * \bar{k}_{i}+\sum_{i} \sigma_{i} * P_{x_{i}} * x_{i}
\end{aligned}
$$

Households and firms pay (direct) tax to the government. Direct tax is levied over taxable income $Y^{t}$. Taxable income comprises primary income and income transfers received from government, from social security, and from abroad. Income transfers paid by government and social security are exogenous in real terms. Nominal transfers are pegged to the consumer price index CPI to maintain purchasing power of households at the benchmark level. The consumer price index is chosen as numeraire of the model and is fixed exogenously. Transfers from abroad are fixed in foreign currency and are transformed to domestic currency by multiplication with the exchange rate ER. Transfers to firms are zero in the SAM; so for firms taxable income is implicitly equal to primary income.

$$
Y_{h}^{t}=Y_{h}^{p}+\overline{\mathrm{o}}_{h g} * \overline{C P I}+\overline{\mathrm{o}}_{h s} * \overline{C P I}+\overline{\mathrm{o}}_{h f} * E R
$$

Disposable income of households and firms $Y_{h}^{d}$ is defined as taxable income minus direct taxes and social security contributions paid. Both social security contributions and direct taxes are fixed proportions ( $\tau_{s h}$ and $\tau_{g h}$, respectively) of taxable income.

$$
Y_{h}^{d}=\left(1-\tau_{s h}-\tau_{g h}\right) * Y_{h}^{t}
$$

Most outlays by social security are fixed in real terms. Nominal transfers paid to domestic and foreign households are pegged to 
the consumer price index, as the objective of the government is to maintain purchasing power of transfer payments. Because savings of social security $s_{s}$ are a provision for future fluctuations in the number of transfers, they are pegged to the consumer price index also. Incomings are primary income and social security contributions paid by households. The budget is balanced by adjusting the net transfers paid to the government $O_{g s}$.

$$
Y_{s}^{p}+\sum_{h} \tau_{s h} * Y_{h}^{h}=\bar{s}_{s} * \overline{C P I}+\sum_{h} \bar{o}_{h s} * \overline{C P I}+\bar{o}_{f s} * \overline{C P I}+O_{g s}
$$

The government budget deficit is defined as incomings minus expenditures. Also for the government expenditures are fixed in real terms. In addition to spending on transfers, government also spends on consumption, of which the volume $c_{i g}$ is fixed exogenously. Incomings are primary income and direct taxes paid by households and firms.

$$
\begin{aligned}
S_{g}= & \sum_{h} \tau_{g h} * Y_{h}^{h}+Y_{g}^{p}-\sum_{i} \bar{c}_{g i} * P_{x_{j}} \\
& -\sum_{h} \bar{o}_{h g} * \overline{C P I}-\bar{o}_{f g} * \overline{C P I}+O_{g s}
\end{aligned}
$$

Consumption expenditure of households is distinguished by want categories $W_{k h}$. For simplicity it is assumed that consumption behavior is determined by Cobb-Douglas utility functions, which generate the following constant budget shares consumption demand functions:

$$
W_{k h}=\gamma_{k h} * Y_{h}^{d}
$$

Wants are composed of domestic goods, distinguished by sector of origin, and imported goods, of which the volume shares $v_{i k}$ and $v_{\mathrm{fk}}$ in the composite are fixed. Thus, no substitution is possible between domestic and imported goods.

Consumption expenditure on imports $M_{k}$ follows from:

$$
M_{k}=\bar{P}_{m_{k}}^{\sharp} * E R * v_{j k}^{*} \sum_{h} \frac{W_{k h}}{P_{w_{k}}}
$$

Total consumption expenditure by sector $Q_{i}$ can be derived in a similar way:

$$
Q_{i}=P_{x_{i}}^{*} \sum_{k} v_{i k} * \sum_{h} \frac{W_{k h}}{P_{w_{k}}}
$$

The price index of wants $P_{w k}$ is a weighted average of all component prices. The weights are the respective shares of the components in the composite. 


$$
P_{w_{k}}=v_{f k} * \bar{P}_{m_{w}}^{\S} * E R+\sum_{i} v_{i k} * P_{x_{i}}
$$

The closure of the model is neoclassical, which implies that domestic investment expenditure $Z$ is determined by the sum of domestic and foreign savings. Total domestic savings are the sum of savings by government, social security, and households and firms, the latter is defined as disposable income minus consumption expenditure. Net foreign savings consist of an exogenous flow $F^{\$}$, which is fixed in foreign currency, and an endogenous flow that is equal to the government budget deficit, as it is assumed that the government finances its total budget deficit by foreign borrowing. As the endogenous part of foreign savings cancels out against net government savings both are excluded from Equation 17.

$$
Z=\bar{F}^{s} * E R+\bar{s}_{s} * \overline{C P I}+\sum_{h} Y_{h}^{d}-\sum_{h} \sum_{k} W_{k h}
$$

It is assumed that there exists only one type of investment good, which is a composite of domestic goods, again distinguished by sector of origin, and imported goods. The volume shares of the delivering sectors in the composite $\xi_{i}$ are fixed. Nominal investment expenditure by sector of origin $I_{i}$ can specified as follows:

$$
I_{i}=P_{x_{i}} * \xi_{i} * \frac{Z}{P_{z}}
$$

The price index of the composite investment $\operatorname{good} P_{z}$ is a weighted average of domestic output prices $P_{x i}$ and the price index of a composite of imported investment goods $P_{m_{Z}}^{\delta}$. The weights are the respective shares of the components in the composite.

$$
P_{z}=\xi_{i}^{*} \bar{P}_{m_{z}}^{\varsigma} * E R+\sum_{i} \xi_{i}^{*} P_{x_{i}}
$$

Domestic products are assumed to compete on the world market with goods produced abroad, which differ by country of origin. This product heterogeneity implies that the world market demand for domestic products depends partly on domestic prices. Then, the value of exports $E_{i}$ can be expressed as follows:

$$
E_{i}=P_{x_{i}}{ }^{*} e_{i}=P_{x_{i}} *\left[\frac{\bar{P}_{e_{i}}^{\varsigma}}{P_{x_{i}} / E R}\right]^{\delta_{i}} * \bar{e}_{i 0}
$$

where $e_{i}$ is the volume of exports, $P_{e i}^{\delta_{i}}$ is the weighted average of the fixed prices of competitors on the world market and $\delta_{i}$ is the world market demand elasticity for domestic products of sector $i$. $\bar{e}_{i 0}$ is a constant term reflecting total world market demand for output of sector $i$ and the domestic market share if $P_{x i} / E R$ is equal 
to $P_{e i}^{\$}$. If it is assumed that the export demand elasticity is equal to one, we get:

$$
E_{i}=\bar{P}_{e_{i}}^{\S} E R * \bar{e}_{i 0}
$$

The balance of payments equation gives on the left-hand side the capital account balance. On the capital account a distinction is made between the inflow of foreign capital needed to finance the government budget deficit $S_{g}$ and other capital flows $F^{\$}$, which are fixed in foreign currency. The right-hand side gives the current account balance, which consists of imports of investment goods, intermediate goods and consumption goods, exports and net income transfers to abroad.

$$
\begin{aligned}
\bar{F}^{\S *} E R+S_{g}= & \bar{P}_{m_{z}}^{\S} E R^{*} \xi_{f} * \frac{Z}{P_{z}}+\sum_{i} \bar{P}_{m_{i}}^{\S} E R^{*} \mu_{i} * x_{i}+\sum_{k} M_{k} \\
& -\sum_{i} E_{i}+\left(\overline{\mathrm{o}}_{f g}+\overline{\mathrm{o}}_{f s}\right) * \overline{C P I}-\sum_{h} \overline{\mathrm{o}}_{h f} * E R
\end{aligned}
$$

Equation 22 gives the product balances. According to Walras' Law only four equations have to be specified, equilibrium on the four markets guarantees equilibrium of the fifth. Output prices $P_{x i}$ can be solved from these equations.

$$
X_{i}=\sum_{j} P_{x_{i}} * \alpha_{i j} * x_{j}+Q_{i}+I_{i}+E_{i}+\bar{c}_{i g} * P_{x_{i}}
$$

The consumer price index is taken as numeraire of the model. The weights are the proportions of the respective products in aggregate household expenditure. This specification implies that changes in household income can be interpreted as changes in real household income.

$$
\overline{C P I}=\sum_{k} \rho_{k} * P_{w_{k}}
$$

To finish this section we will discuss the comparability of the CGE and SAM model. The CGE model described above employs, except for prices, wage, and exchange rate, the same assumptions as the SAM model reported in the previous section.

In the SAM model government, social security, and the rest of the world are exogenous. Exogenity implies in this context that payments by these actors to endogenous actors are fixed. Because prices are fixed, this specification corresponds to the specification in the CGE model. Here government expenditure is fixed in real terms. The same is true for transfers paid by the rest of the world. Exports are determined by relative prices only, so that in the case of price fixation they would become fixed as well. 
Incomings of exogenous actors are not constant in the SAM model, but are proportional to expenditures by endogenous actors. Thus, incomings of government depend among others on tax payments by activities, households, and firms. Incomings of social security are a fixed share of the total wage sum, while incomings of the rest of the world are payments for imports, which are proportional to domestic activities, consumption, and investment.

In the aggregate, total incomings of the exogenous sectors will be equal to total expenditures, including policy injections. For individual accounts this does not have to be the case, because increased expenditure by the government leads to higher receipts by social security and the rest of the world through higher social security contributions and higher imports. To achieve that the three exogenous accounts are not only in equilibrium in the aggregate but also separately, two additional assumptions are made in the SAM model. First, the budget surplus of social security is fixed, and every increase in receipts by this institution will be compensated by an increase in its contribution to the government. The same closure of the social security budget is chosen in the CGE model. Second, the remaining increase of the government budget deficit will be financed by the rest of the world. Also this assumption is applied in the CGE version.

The capital account is taken endogenous in the SAM model. This is consistent with the savings-driven investment specification in the CGE model.

Finally, it may be remarked that in case of fixed prices all equations that assume substitution are reduced to fixed coefficient specifications similar to those that are used in the SAM model. For instance, the factor demand Equations 5 and 6 will be reduced to Leontief-type specifications if it would be assumed that price indices remain at their benchmark levels, which are unity. So, the difference in price regime and the accompanying assumptions about the constraints on total supply of labor, capital, and foreign savings form the only ground for differences in simulation results between the CGE model and the SAM model.

\section{THE RESULTS OF SIMULATIONS: THE POLISH CASE}

\section{A. Introduction}

To demonstrate the different consequences of government policy under the two opposite regimes of central planning (fixed prices) and free market (flexible prices), two government policy measures 


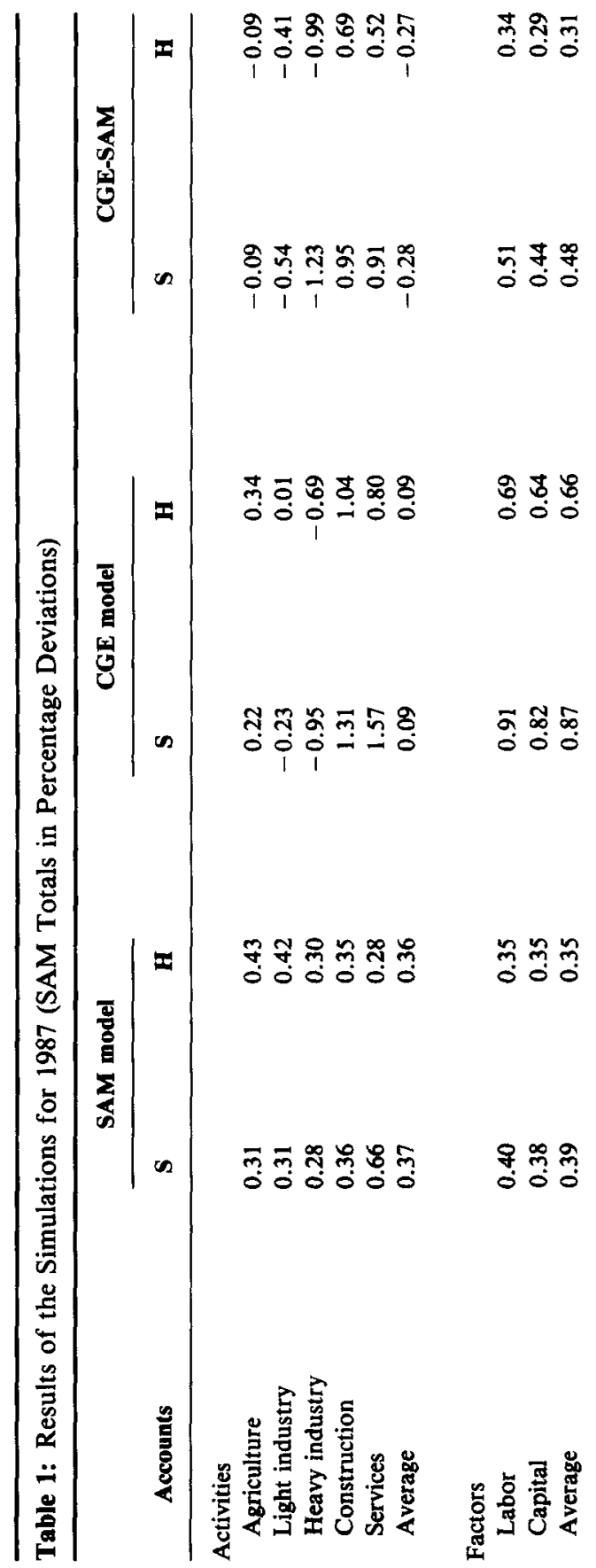




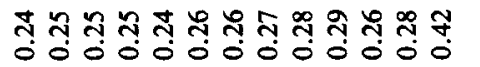

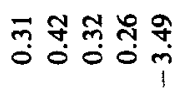

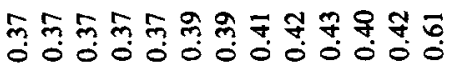

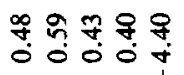

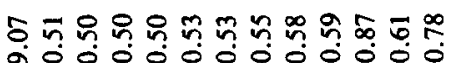

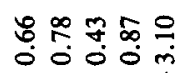

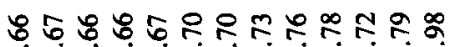
ஸ。ำำำ O000000000000 00000

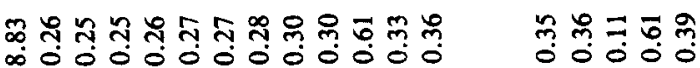

तิ 
are simulated under both price regimes, one aimed at shifting the production structure towards services, the other aimed at changing the income distribution in favor of the poorest households. In the first, Experiment S, government demand for services is increased by 1 percent of total government expenditure. The measure can be interpreted as been taken to reduce the bias against the underdeveloped service sector inherited from the old planning system. In the second, Experiment $\mathrm{H}$, the same amount is transferred as welfare payments to the lowest decile household group, which can be interpreted as a measure to reduce the adverse effects of transition for the poorest households.

The exogenous impulse of 1 percent of total government expenditure was equal to 31.197 bill.zl for 1987 and 1.144 th.bill.zl for 1990. The results of the simulations are presented in Tables 1 to 4. The results will be discussed for each simulation ( $\mathrm{S}$ and $\mathrm{H}$ ) and each price regime (fixed price SAM model and flexible price CGE model) separately and for both years simultaneously.

\section{B. Variant S: Increase in Government Demand for Services}

The SAM MoDel. As can be expected, additional expenditures of government in services lead to increased output of services (by $0.66 \%$ in 1987 and $0.67 \%$ in 1990). Output of other activities adjust complementarily according to input-output ties with no limits for factors supplies. Construction, which has the strongest forward linkage, responds most. Factor incomes grow with increasing output at approximately the same rate $(0.39 \%$ in 1987 and $0.40 \%$ in 1990). Labor incomes are affected slightly more than capital, because of the shift in branch output composition towards laborintensive branches. On average, factors reacted more than activities, because branches that expanded were more value-added intensive than the economy on average. With rising factor incomes, institutions increased their income: households by 0.32 percent in 1987 and 0.31 percent in 1990 , firms by 0.37 percent in 1987 and $0.39 \%$ in 1990 . Thus, firms profited more than households despite the fact the labor factor incomes grew more than capital. Two reasons may be given to explain these results. First, there is relatively large leakage from the labor account to exogenous accounts (over $20 \%$ in both years). Second, household incomes are substantially dependent on exogenous sources (about 22\% in 1990). Among households, the rich gain much more than the poor, which may 
Table 2: Results of the Simulations for 1987 (Price and Quantity Variables in Percentage Deviations)

\begin{tabular}{|c|c|c|c|c|c|c|c|c|}
\hline \multirow[b]{3}{*}{ Activities } & \multicolumn{6}{|c|}{ CGE model } & \multirow{2}{*}{\multicolumn{2}{|c|}{$\begin{array}{c}\text { CGE-SAM } \\
\text { Real output }\end{array}$}} \\
\hline & \multicolumn{2}{|c|}{ VA prices } & \multicolumn{2}{|c|}{ Output prices } & \multicolumn{2}{|c|}{ Real output } & & \\
\hline & $\mathbf{S}$ & $\mathbf{H}$ & $\mathbf{s}$ & $\mathbf{H}$ & $\mathbf{s}$ & $\mathbf{H}$ & $\mathbf{s}$ & $\mathbf{H}$ \\
\hline Agriculture & 0.81 & 0.67 & 0.42 & 0.36 & -0.21 & -0.02 & -0.52 & -0.45 \\
\hline Light industry & 0.71 & 0.68 & -0.05 & 0.02 & -0.18 & -0.01 & -0.49 & -0.43 \\
\hline Heavy industry & 0.09 & 0.09 & -0.32 & -0.23 & -0.63 & -0.46 & -0.91 & -0.76 \\
\hline Construction & 1.71 & 1.33 & 0.74 & 0.58 & 0.57 & 0.46 & 0.21 & 0.11 \\
\hline Services & 1.53 & 0.94 & 0.84 & 0.50 & 0.72 & 0.30 & 0.06 & 0.02 \\
\hline
\end{tabular}

be explained by much more dependency of the latter on exogenous incomes. For example, transfers constituted 85.4 percent of total income of the $1^{\text {st }}$ decile group, while it comprised only 4.8 percent of total income of the $10^{\text {th }}$ decile group in 1990. As far as outlays of institutions are concerned, savings increased more than consumption (i.e., $0.40 \%$ vs. $0.31 \%$ in 1990). This can be explained by (1) higher income growth of firms than households, and (2) higher propensity to save of firms than households (viz., $53.6 \%$ vs. $21.8 \%$ in 1990). Direct taxes grow - by definition - by the same rate as the incomes of institutions and indirect taxes by the same rate as output. Increasing tax revenues provide the budget with resources for financing additional expenditures for services.

Generally, the initial impulse results in GDP growth of 0.39 percent in 1987 and 0.40 percent in 1990, with investments growing faster than individual consumption (viz., $0.79 \%$ vs. $0.32 \%$ in 1987 , and $0.40 \%$ vs. $0.41 \%$ in 1990 ).

THE CGE Model. As in the SAM model, additional government demand for services is satisfied by an increase in the output of services (by $1.57 \%$ both in 1987 and 1990). Because total factor supplies are given, part of the increase in demand disappears into a rise in the price index $(0.84 \%$ in 1987 and $0.92 \%$ in 1990$)$, so that the real increase in services output is much smaller: 0.72 percent in 1987 and 0.65 percent in 1990 . Moreover, as factor supplies are given, the rise in output of services can now be realized only through reallocation of factor supplies from other activities; this is restricted to the allocation of labor, because capital is immobile. 


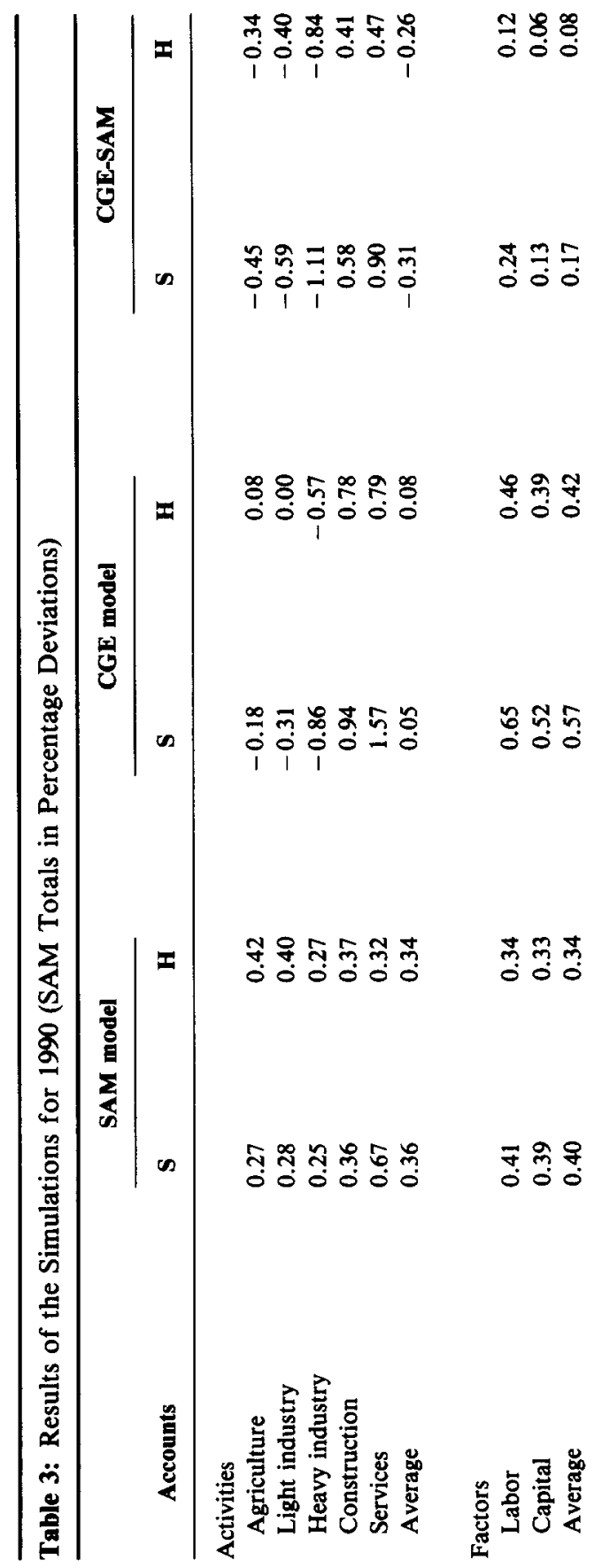




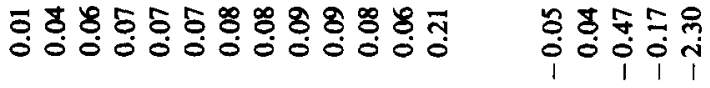

웅웡 者

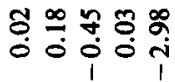

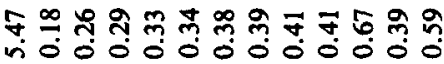

ำ

00001

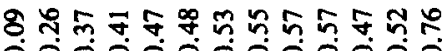

กำ

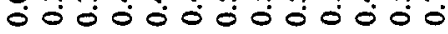

○ं。்

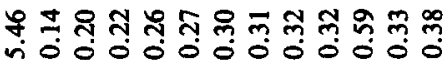

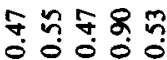

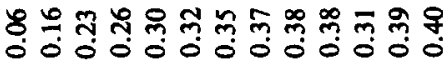

nึ 워

0000000000000 00000

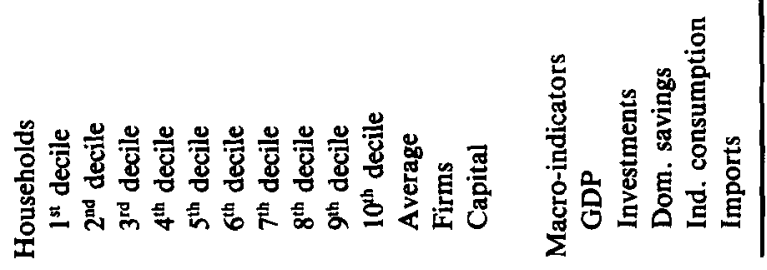


Table 4: Results of the Simulations for 1990 (Price and Quantity Variables in Percentage Deviations)

\begin{tabular}{|c|c|c|c|c|c|c|c|c|}
\hline \multirow[b]{3}{*}{ Activities } & \multicolumn{6}{|c|}{ CGE model } & \multirow{2}{*}{\multicolumn{2}{|c|}{$\frac{\text { CGE-SAM }}{\text { Real output }}$}} \\
\hline & \multicolumn{2}{|c|}{ VA prices } & \multicolumn{2}{|c|}{ Output prices } & \multicolumn{2}{|c|}{ Real output } & & \\
\hline & $\mathbf{S}$ & $\mathbf{H}$ & $\mathbf{S}$ & $\mathbf{H}$ & $\mathbf{S}$ & $\mathbf{H}$ & $\mathbf{s}$ & $\mathbf{H}$ \\
\hline Agriculture & 0.48 & 0.41 & 0.17 & 0.17 & -0.36 & -0.10 & -0.63 & -0.52 \\
\hline Light industry & 0.30 & 0.40 & 0.08 & 0.04 & -0.23 & -0.04 & -0.51 & -0.44 \\
\hline Heavy industry & -0.24 & -0.14 & -0.37 & -0.24 & -0.49 & -0.33 & -0.74 & -0.60 \\
\hline Construction & 1.50 & 1.17 & 0.50 & 0.42 & 0.43 & 0.36 & 0.07 & -0.01 \\
\hline Services & 1.39 & 0.78 & 0.92 & 0.51 & 0.65 & 0.28 & -0.02 & -0.04 \\
\hline
\end{tabular}

The mechanism goes along the following lines: The government budget deficit rises through the increase in spending. It is assumed that the credit-worthiness of the government is sufficient to enable it to finance the deficit by foreign borrowing. This leads to an increase in the supply of foreign currency, inducing an appreciation of the zloty: The exchange rate has to decrease by -4.13 percent in $1987(1990:-2.69 \%)$ to restore equilibrium on the balance of payments. The appreciation deteriorates the competitive position of Polish exporters, and exports will decrease. So, exports carry the burden of the macroeconomic adjustment and have to given in to make the expansion of government consumption possible.

On the sectoral level it is heavy industry, which is to a large extent reliant on exports, that suffers most from the adjustment. Real output decreases by -0.63 percent in $1987(-0.49 \%$ in 1990$)$. The decrease in the production levels of agriculture and light industry is less pronounced. Both sectors have a more diversified demand structure and are less vulnerable to changes in the pattern of final demand. Surprisingly, construction does not suffer at all from the expansion of services, production has increased by 0.57 percent in 1987 (1990: 0.43\%). This is caused by the boost in investment expenditure that amounts to 0.96 percent in $1987(0.76 \%$ in 1990).

An important additional effect of the appreciation of the zloty is a strong improvement in the terms of trade, which is manifested by high value-added prices. This leads, in spite of fixed resources, to a considerable increase in the total value-added or GDP, namely by 0.87 percent in 1987 and 0.57 percent in 1990 .

The rise in factor payments results in an increase in household income averaging 0.72 percent $(1990: 0.47 \%$ ). The rise in household 
income is smaller than the rise in factor payments, because part of household income stems from fixed income transfers. The income distribution becomes more unequal in 1990 than in 1987, which can be explained by the fact that the share of transfers, which are fixed in real terms, in the income of the poorest households has increased significantly in three years time.

Private consumption increases through the rise in household income by 0.72 percent in 1987 (1990: $0.48 \%$ ). Higher household and firm incomes result in higher tax receipts by the government. This mitigates the initial increase in the budget deficit, so that in the end the increase in private and foreign savings dominates the decrease in government savings. The neoclassical closure of the model implies that investment will rise at a rate equal to the increase in total savings: 0.96 percent in 1987 and 0.76 percent in 1990 .

It can be concluded that private consumption, investment, and government demand have increased at the expense of exports, or, to put it differently, the Polish economy has benefited from the government policy at the expense of the rest of the world.

\section{C. Variant H: Additional Government Transfer to $1^{\text {st }}$ Decile Household Group}

THE SAM MoDEL. The results show that the additional transfer to the lowest income decile raises this decile's income by 8.83 percent in 1987 and by 5.46 percent in 1990 . Incomes of other decile groups grow only a litte because of the low share of the $1^{\text {st }}$ decile group in the total of household incomes (viz., 3.8\% in 1987 and $6.1 \%$ in 1990) and the absence of direct transfers among household groups. On average, household income grows only by 0.61 percent in 1987 and by 0.59 percent in 1990 . Increased incomes together with an altered decile distribution generated increased consumption with a changed pattern. As might be expected, foodstuffs and other necessities increased most. Increasing consumption demand has been covered by growing output: mainly by light industry (viz., $0.42 \%$ in 1987 and $0.40 \%$ in 1990 ) and agriculture (viz., $0.43 \%$ in 1987 and $0.42 \%$ in 1990). Increasing output requires additional factor inputs. As a consequence, factor incomes increase by 0.35 percent in 1987 and by 0.34 percent in 1990, with labor and capital growing at approximately the same rate, as agriculture is relatively labor-intensive while light industry is relatively capital-intensive. 
Generally, the economy reacts to additional government transfers to lowest household group by moderate growth of all its macroindicators. GDP increases by 0.35 percent in 1987 and by 0.34 percent in 1990.

The CGE Model. In the CGE model, additional government transfers to the lowest decile household group results in significant increases in incomes of those households (by $9.05 \%$ in 1987 and $5.47 \%$ in 1990). Other households' income also increased, which are the consequence of the improvement in the terms of trade resulting from the appreciation of the zloty. As in the previous experiment, the appreciation is caused by an increased inflow of foreign capital to finance the government budget deficit. It should be remarked here that these mechanisms are incorporated in the model and that the appreciation and accompanying improvement in terms of trade do not arise from the fact that the injection is implemented by the government. A transfer by the rest of the world to the poorest households would have given almost exactly the same results.

Total consumption expenditure increases by approximately the same rate as the average of household incomes, but its pattern changes towards a larger share of foodstuffs and other necessities. Consumption demand has increased more than in the previous experiment, which follows from the fact that in the current experiment household incomes are affected directly by the government impulse, while in the previous experiment incomes were only indirectly influenced. The large increase in consumption, and the consumption of foodstuffs in particular, has a favorable effect on the production of agriculture and light industry. However, this impact is not enough to offset the decrease in these activities' export earnings so that real production in agriculture and light industry decreases by -0.02 percent and -0.01 percent, respectively, in 1987 (1990: $-0.10 \%$ and $-0.04 \%$, respectively). Services expand by 0.30 percent in $1987(0.28 \%$ in 1990$)$, mainly through trade, which increases with consumption and investment. The increase in investment also causes a sharp rise in the production level of construction: $\mathbf{0 . 4 6}$ percent in 1987 and 0.36 percent in 1990 . Heavy industry undergoes the largest decline in production, resulting from its strong dependence on exports.

Also in the case of an additional government transfer from the government to the lowest decile household group, consumption and investment increase, this time the increase in the former slightly 
larger than in the latter. Again, exports have to give in to realize the increase in domestic demand.

\section{D. Flexible Versus Fixed Prices: A Comparison}

To analyze the impact of the switch in price regime on the real output of activities, changes in price and quantity variables are presented separately in Tables 2 and 4 . It can be seen that heavy industry is performing much worse under a flexible price regime. Depending on the type of experiment and year the change in output is -0.60 to -0.91 percentage point lower than under a fixed-price regime. Agriculture and light industry are also performing worse under the flexible-price regime. The change in real output is for agriculture up to -0.63 and for light industry up to -0.51 percentage point lower. Generally construction is performing better under a flexible-price regime. Services are performing better under a flexible-price regime in 1987 and better under a fixed-price regime in 1990.

Despite the fact that total resources are given under the flexibleprice regime, the increase in household income generated by government injections is higher than under the fixed-price regime. Average household income in 1987 is 0.40 percentage point higher in the services experiment and 0.26 percentage point in the transfer experiment. Under the flexible-price regime the price changes, more in particular a decrease in the exchange rate, are responsible for the increase in real household income. However, because total resources are fixed, price changes cannot generate a rise in income for all actors in the system; they can only redistribute income between actors. In this model the rest of the world pays for the increase in domestic incomes. Of course, the favorable impact of the increase in foreign borrowing only holds for the short term. In the longer run, debts have to be amortized and interest has to be paid. However, the same argument holds under the fixed-price regime, where also a foreign capital inflow is needed to compensate for the imbalance on the current account, because imports increase proportional to domestic expenditures while exports are fixed.

For 1990 the difference in impact on household income between both price regimes is less pronounced. This holds for both experiments. This smaller difference can be explained by the smaller change in the exchange rate in 1990 . The lower exchange rate results from the increase in exports relative to imports between 1987 and 


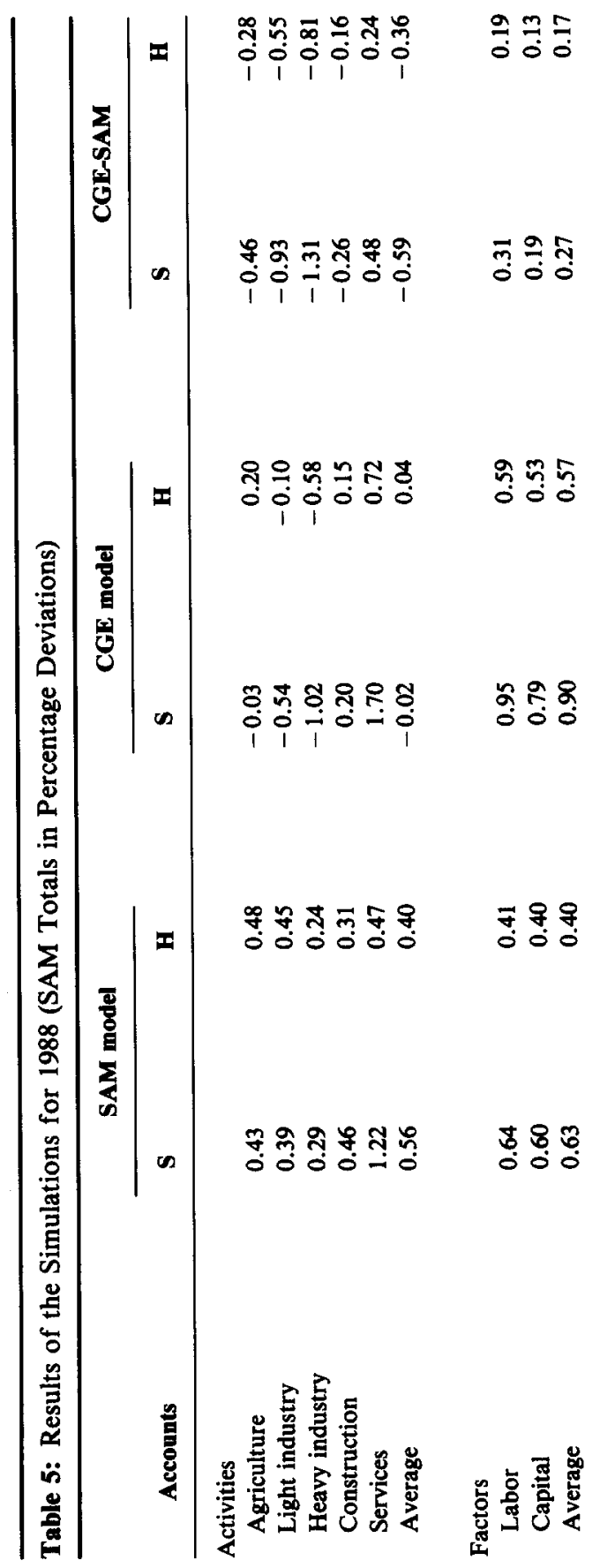




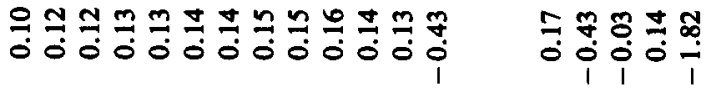

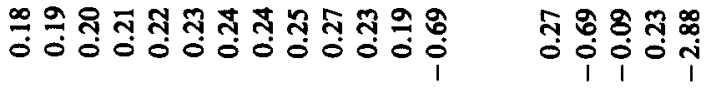

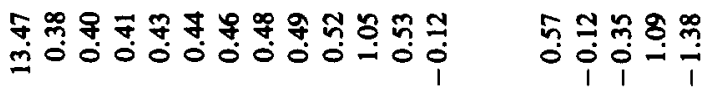

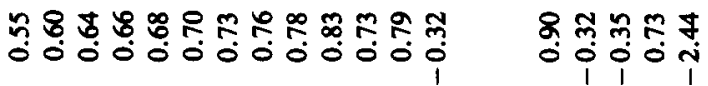

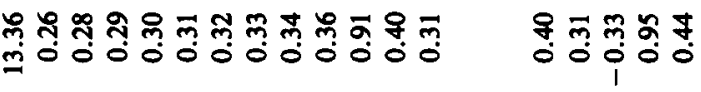

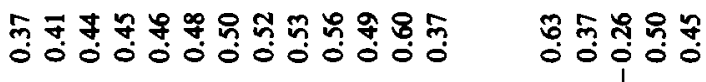


1990. Higher exports facilitate the adjustment to balance of payments equilibrium, because the adjustment takes place mainly through changes in exports, because imports are non-competitive and thus do not react directly to changes in the exchange rate.

So, in conclusion we can say that the level of exports relative to imports plays an important role in determining the effect a transition will have on household incomes. Apart from this, the effect does depend on the assumed substitution elasticities. For the current simulations, we have chosen specifications that allowed all parameters to be calibrated by the SAM, which implicitly means that the substitution elasticity was zero for import demand and unity for export demand. For future simulations it will be useful to use substitution elasticities with greater empirical relevance.

\section{THE RESULTS OF SIMULATIONS: THE HUNGARIAN CASE}

\section{A. Introduction}

The SAM and CGE models were also calibrated on SAMs for Hungary on a pre-transition and a transition year, (Cohen, 1993). Because no SAM for 1987 was available, the 1988 SAM was chosen as a pre-transition SAM, and the 1990 SAM was chosen as a transition SAM.

Because the format of the Hungarian SAM deviates from the format of the Polish SAM, some minor adjustments in the CGE model were necessary. ${ }^{5}$

The two experiments undertaken with the Polish model were repeated for Hungary. In the first experiment (Variant S) government's demand for services was increased by 1 percent of total government expenditure, whole in the second experiment (Variant H) the transfers to the poorest household group were increased by the same amount. The impulse was equal to 5.668 billion forints

\footnotetext{
${ }^{3}$ The adjustments are the following:

1. Capital income in Hungary is not distributed directly to the households as a total proportion of capital income, but flows to the firms and is distributed over the households as a fixed proportion of firm income.

2. Government sector also comprises social security.

3. Firms are allowed to buy consumption goods.

4. Indirect taxes are levied not only on production but also on consumption and imported investment goods.
} 
Table 6: Results of the Simulations for 1988 (Price and Quantity Variables in Percentage Deviations)

\begin{tabular}{|c|c|c|c|c|c|c|c|c|}
\hline \multirow[b]{3}{*}{ Activities } & \multicolumn{6}{|c|}{ CGE model } & \multirow{2}{*}{\multicolumn{2}{|c|}{$\frac{\text { CGE-SAM }}{\text { Real output }}$}} \\
\hline & \multicolumn{2}{|c|}{ VA prices } & \multicolumn{2}{|c|}{ Output prices } & \multicolumn{2}{|c|}{ Real output } & & \\
\hline & $\mathbf{S}$ & $\mathbf{H}$ & $\mathbf{S}$ & $\mathbf{H}$ & $\mathbf{S}$ & $\mathbf{H}$ & $\mathbf{S}$ & $\mathbf{H}$ \\
\hline Agriculture & 0.90 & 0.59 & 0.26 & 0.19 & -0.29 & 0.01 & -0.72 & -0.47 \\
\hline Light industry & 0.67 & 0.58 & -0.22 & -0.08 & -0.32 & -0.02 & -0.72 & -0.47 \\
\hline Heavy industry & 0.43 & 0.30 & -0.24 & -0.13 & -0.78 & -0.45 & -1.07 & -0.69 \\
\hline Construction & 0.92 & 0.58 & 0.30 & 0.20 & -0.10 & -0.04 & -0.56 & -0.35 \\
\hline Services & 1.40 & 0.75 & 0.68 & 0.36 & 1.02 & 0.35 & -0.20 & -0.12 \\
\hline
\end{tabular}

in 1988 and to 9.065 billion forints in 1990 . The simulation results for 1988 can be found in Tables 5 and 6, and results for 1990 are shown in Tables 7 and 8.

In both models, 1 percent increase in government expenditure (in real terms) leads to a fall in government saving. In the SAM multiplier model, this is very trivial: A unitary exogenous injection always generates a one-unit increase in spending on exogenous accounts (leakages), which are the taxes (government) and imports (R.O.W.) in our model. So, because the injection leaks partly to imports, government income increases less than expenditures, and this implies less saving. In the CGE model a similar result can be found: Tax revenues are proportional to the (intermediate and final) consumption of the individual agents; so domestic consumption should increase by 1 percent (in real terms too) in order to maintain the original level of government saving. However, real output and real value-added are fixed in average in the CGE model due to resource constraints. So domestic real income and real consumption can increase only if the domestic currency appreciates significantly to make imports cheaper (the export part of the revenues is proportional to the domestic price due to the special assumptions for the calibration of the model).

The fall in government saving (the "growing deficit") induces a counterbalancing decrease in the flow of savings to abroad (debt repayments by the government are reduced). In the SAM model this only implies that accumulation grows slower than other items (because this part of the saving is constant). However, in the CGE model it leads to a drop in real accumulation (even nominal accumulation is decreasing in all but one CGE simulation). The decrease 


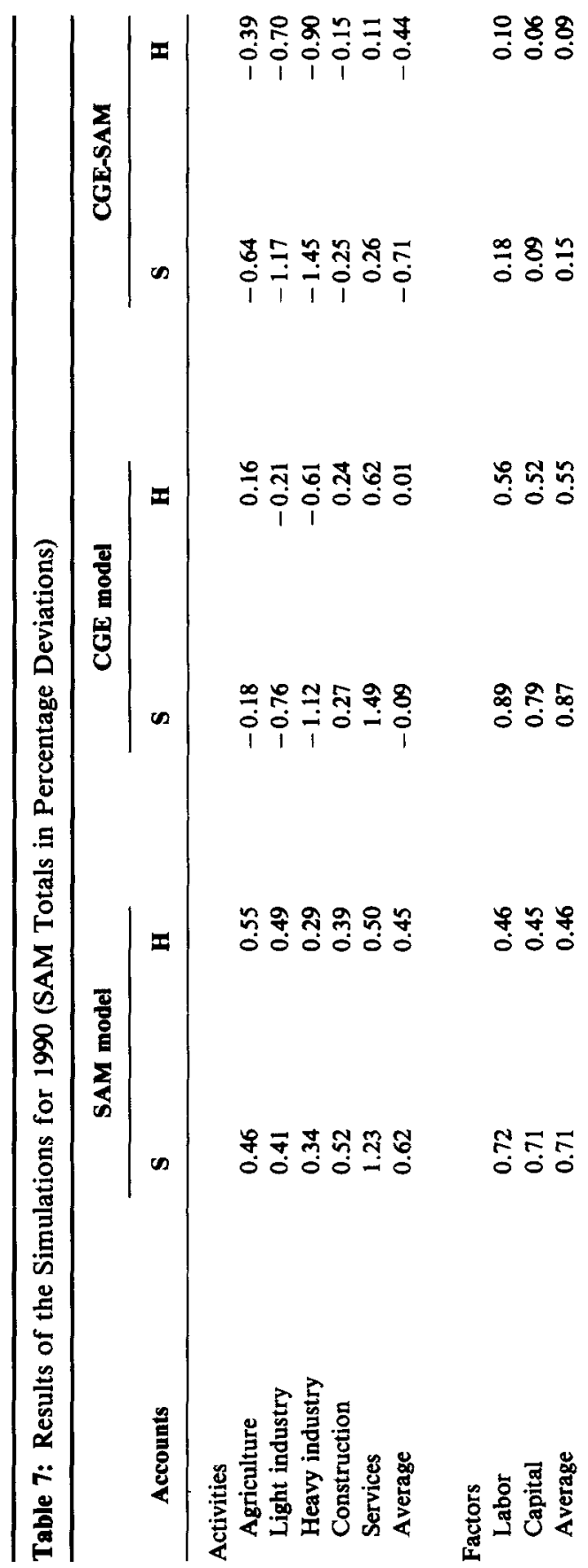




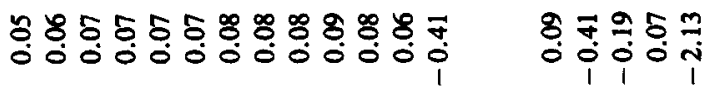

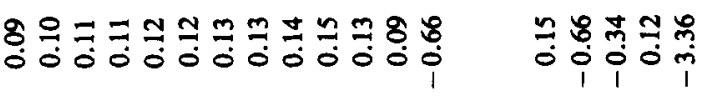

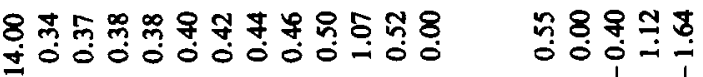

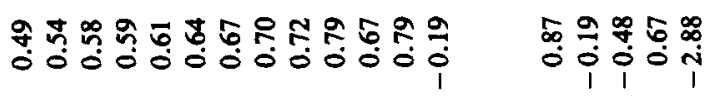

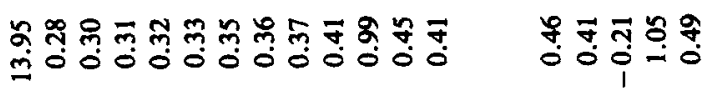

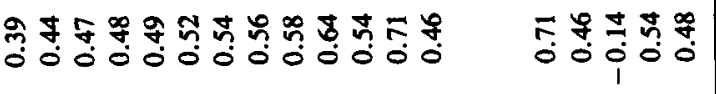

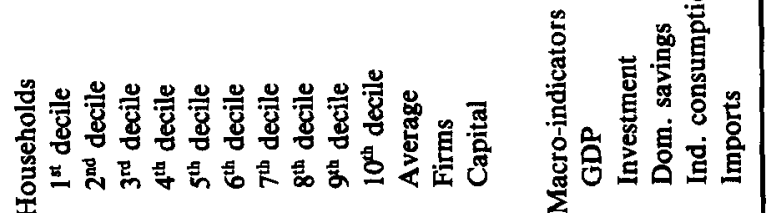


Table 8: Results of the Simulations for 1990 (Price and Quantity Variables in Percentage Deviations)

\begin{tabular}{|c|c|c|c|c|c|c|c|c|}
\hline \multirow[b]{3}{*}{ Activities } & \multicolumn{6}{|c|}{ CGE model } & \multirow{2}{*}{\multicolumn{2}{|c|}{$\frac{\text { CGE-SAM }}{\text { Real output }}$}} \\
\hline & \multicolumn{2}{|c|}{ VA prices } & \multicolumn{2}{|c|}{ Output prices } & \multicolumn{2}{|c|}{ Real output } & & \\
\hline & $\mathbf{s}$ & $\mathbf{H}$ & $\mathbf{S}$ & $\mathbf{H}$ & $\mathbf{s}$ & $\mathbf{H}$ & $\mathbf{S}$ & $\mathbf{H}$ \\
\hline Agriculture & 0.84 & 0.57 & 0.18 & 0.15 & -0.36 & 0.01 & -0.82 & -0.54 \\
\hline Light industry & 0.58 & 0.52 & -0.33 & -0.14 & -0.44 & -0.06 & -0.85 & -0.43 \\
\hline Heavy industry & 0.47 & 0.34 & -0.29 & -0.16 & -0.83 & -0.45 & -1.17 & -0.74 \\
\hline Construction & 0.89 & 0.57 & 0.28 & 0.19 & -0.01 & -0.05 & -0.53 & -0.34 \\
\hline Services & 1.24 & 0.67 & 0.65 & 0.35 & 0.83 & 0.26 & -0.40 & -0.24 \\
\hline
\end{tabular}

in debt repayments reduces the demand for foreign currency; the exchange rate appreciates, and this reduces the domestic value of foreign currency in fixed savings. Non-government domestic savings are proportional to the income of the corresponding agents; the increase in this variable is insufficient to counterbalance the fall in the domestic value of foreign savings. In CGE simulations the growing domestic consumption is counterbalanced by the fall in export, which is reached by the appreciation of the exchange rate. The simulation results will be discussed in detail below.

\section{B. The Variant S: Increase in Government Demand for Services}

THE SAM Model. In Hungary the increase in government spending on services equal to 1 percent of total government income elevates the production value of services by approximately the same percentage for both years under study: 1.22 percent and 1.23 percent, respectively, which is significantly higher than the increase that was found for Poland. This can be explained by the larger government sector in Hungary. Because the injection is equal to 1 percent of the government budget, this implies that the impulse will be a higher percentage of benchmark production than in Poland. As a result, the average rise in production value (0.56 in 1988 and 0.62 in 1990) is also higher than in Poland. As in the Polish simulations, construction shows the second largest output growth. Heavy industry shows the smallest increase in output, namely 0.29 percent in 1988 and 0.34 percent in 1990, which does not differ much from the increase that was found for Polish heavy industry. 
So, in Hungary the injection leads to a larger sectoral dispersion than in Poland.

The rise in factor remunerations is higher $(0.63 \%$ in 1988 and $0.71 \%$ in 1990) than the increase in averageproduction value, which can be attributed to the high value-added intensity of services. Labor income rises only slightly more than capital income, which corresponds with the results that were found for Poland.

The change in average household income is lower than the change of factor income for the same reason mentioned in the previous section. The small share of endogenous components in the income of the lower deciles makes that impulse lead to a more unequal distribution of income. Contrary to the Polish simulations, in which the distribution of income has become less equal over time, the distribution of income was fairly stable over time in the Hungarian simulations.

THE CGE Model. In Hungary the macro adjustment to external shocks goes along the same lines as in Poland. The increase in government spending leads to a decline in the government budget surplus and results in a cutback of net debt amortization by the government, which reduces the demand for foreign currency so that the forint appreciates. The decrease in the exchange rate amounts to -2.29 percent in 1988 and to -2.69 percent in 1990 . The resulting decrease in exports makes possible the expansion of government (in the services experiment) and private consumption (in the transfer experiment).

Contrary to the Polish situation, there is no boost in investment expenditure in Hungary. The reason for this is the high exogenous inflow of foreign capital. The fall in the exchange rate reduces the domestic value of these foreign savings, and this offsets the increase in domestic savings resulting from increased incomes. The outcome is a small decline in investment expenditure.

On the sectoral level, construction is least affected by the shift towards the service sector, because its strong linkages with investment have a stabilizing effect on its output, while direct injections to services have also a favorable impact on its output level. The latter fact is due to the high construction intensity of services. The output of construction declines in real terms by -0.10 percent in 1988 and by -0.01 percent in 1990 , while in nominal terms its output increases by 0.20 percent and 0.24 percent, respectively. Agriculture and light industry undergo a considerable decline in real output: -0.29 percent and -0.32 percent, respectively in 1988 
( $-0.36 \%$ and $-0.44 \%$ in 1990 ); however, for light industry, nominal output has decreased even more, because the output price also has decreased. Heavy industry suffers the most because of its strong dependence on declining exports. The decline in real output amounts to -0.78 in $1988(-0.83 \%$ in 1990), which is much larger than in the Polish simulations. The increase in the service sector $(1.02 \%$ in 1988 and $0.83 \%$ in 1990) is much larger than in the Polish simulations. Thus in the CGE experiments the sectoral dispersion also is larger for Hungary than for Poland.

The growth in labor income exceeds the growth in capital income by 0.16 percentage point in 1988 and 0.1 percentage point in 1990 . This difference is caused by the decline of output of the capitalintensive industrial sectors.

Average household income increases by 0.73 percent in 1988 and by 0.67 percent in 1990 . Also, for CGE simulations the distribution of income becomes more unequal.

\section{C. Variant H: Additional Government Transfer to $1^{\text {st }}$ Decile Household Group}

The SAM Model. The additional transfer rises the income of the poorest household group by 13.36 percent in 1988 and 13.95 percent in 1990. Again, this is much larger than the increase that was found in the Polish simulations. Also, the average increase in household income, which amounts to 0.91 percent in 1988 and 0.99 percent in 1990, is larger than in Poland.

The average increase in consumption is higher than the increase in average household income (0.95\% in 1988 and $1.05 \%$ in 1990), because the poorest household has a propensity to consume that is above the average. The consumption of foodstuffs, not shown in the table, increases most; its growth is 1.11 percent in 1988 and 1.23 percent in 1990 . The large increase in foodstuff consumption has a favorable impact on the performance of agriculture. Among the activities, agriculture shows the largest expansion of production, while two other activities with strong linkages with consumption, services and light industry, are only slightly behind. Construction experiences only a moderate increase in its output, because the growth in investment stays behind the growth in consumption. Again, heavy industry is the worst performing sector, resulting from its strong reliance on (fixed) exports. In general, the exportoriented industrial sectors have to suffer the most from the constancy or fall in export demand (due to appreciation of domestic 
currency). On the other hand, they are the most import-intensive sectors; so cheaper imports slightly compensate them for the loss of revenue. Loss of their revenue is partly due to the decrease in their output prices (by $0.1 \%-0.3 \%$ ).

THE CGE Model. The additional transfer increases the income of the lowest decile by 13.47 percent in 1988 and 14.0 percent in 1990. Average household income increases by 1.05 percent in 1988 (1990: $1.07 \%$ ). Average consumption increases by 1.09 percent in 1988 (1990: 1.12\%); foodstuffs benefit most. On the sectoral level, output of agriculture is positively influenced by the increase in consumption and negatively by the fall in exports and the fall in output of light industry, to which it has strong forward linkages. Both effects outweigh each other, and ultimately there is hardly any change in output. Heavy industry suffers the most; real output declines by 0.45 percent, both in 1988 and 1990 . The decline is caused by the decrease in export earnings. In nominal terms the decline is reinforced by a fall in the output price. For the same reason real output of light industry falls slightly. The service sector benefits most from the increase in transfers to the poorest household; its real output rises by 0.35 percent in 1988 and by 0.26 percent in 1990. Services are strongly linked to consumption, while they are not affected by the constant or falling export demand. Constant government consumption of services in case of injections to the poorest households can be viewed as a stabilizing factor in CGE models (because total output is fixed), but in SAM multiplier models it pulls back the growth of its output.

Though in the individual sectors labor and capital income change at the same rate due to the assumptions of the model, the expansion of the service sector, which has a small bias in favor of labor, combined with the worse performance of the capital-intensive industrial sectors has the effect that labor incomes grows slightly more than capital income. Average factor income or GDP grows by 0.57 percent in 1988 and 0.55 percent in 1990.

Without additional government transfers to households, the income of households lags behind labor income because the non-labor components of household income are either constant (in the case of transfer income) or grows slower than labor income (in the case of capital income). Because the lower deciles receive a high percentage of their income from the government (the poorest decile receives almost half of its income from the government), increasing labor income generates income mainly for the richest deciles. 


\section{D. Flexible Versus Fixed Prices: A Comparison}

The differences in real output levels between the flexible-price regime and the fixed-price regime are shown in Tables 6 and 8. It can be seen that in real terms all activities perform worse under a flexible-price regime. The largest difference can be found for heavy industry; the change of real output is between 0.69 and 1.17 percentage point, depending on type of experiment and year, lower under the flexible-price regime, which can be attributed to the decrease in export earnings. A shift in the price regime affects agriculture and light industry to almost the same degree; under the flexible-price regime their performance is 0.43 to 0.85 percentage point worse. Contrary to the Polish simulations, construction also is performing worse; the change in its output level is 0.35 to 0.56 percentage point below the change achieved under the fixed-price regime. Services show the smallest differences between the two price regimes; real output is only 0.12 to 0.40 percentage point lower under the flexible-price regime. It is the only sector that shows a better performance in nominal terms.

Although under the flexible-price regime resources constrain output and the general price level is fixed at base level, household income and expenditure grows even more than in the fixed-price simulations. This is mainly due to the lowered exchange rate, which make imports cheaper. The distribution of income is more unequal, because the higher level of household income is entirely the result of an increase in factor incomes (because transfer income is fixed in real terms), which have a bias towards the higher deciles. The difference in income changes between the two price regimes has reduced over time. In 1988 the increase in household income was in the services experiment 0.24 percentage point lower and in the transfer experiment 0.14 percentage point lower under the fixed price regime; in 1990 this was only 0.13 and 0.08 percentage point, respectively.

\section{CONCLUDING REMARKS}

The results reported above illustrate the differences in the simulated behavior of the economy under centrally planned and market regimes. Based on arguments given above, we interpret the results of the SAM model as describing stylized centrally planned economy and we treat the results of the CGE model as reflecting ideal market mechanisms. However, the application of SAM and CGE models to any one country is not meant to replicate a centrally planned and 
a free-market economy, respectively, for that country. It should be mentioned that what we generate in either the SAM or the CGE model are potentials. In the SAM model the impact multipliers are potentials because the ex post realization of any multiplier effect in any country cannot be accurately predicted by any model. It should be remarked here, too, that the alternative allocation of quantities and relative prices are also a potential; this is so because even in the most free market economy, there are deviations between the assumptions of a CGE model and the real situation. And what we study then is a comparison among potentials representing opposite poles.

In the centrally planned economy simulation case, each type of exogenous shock leads to smooth adjustments of other magnitudes. Increasing government demand for services is met by, in a sense, costless growth of output of services and all backward-linked activities. The "costless" adjustment mean here that the central planner is able to enlarge the production capacities of the sectors according to their needs through investment and employment policy. Thus, no bottlenecks emerge. Higher output generates higher incomes of factors and then higher incomes of factor owners (institutions). Those incomes are spent on consumption and are saved/invested. Consumption and investment expenditures amplify the production effect of the initial injection. Prices are assumed not to change, which is consistent with no constraints on production capacities in the SAM model. The same mechanisms are at work in the second simulation when an additional government transfer to the lowest decile household group has been injected into economy. Higher incomes induce larger consumption and investment expenditures that are met by increasing output. As before, it is assumed that there are no rigidities hampering the adjustment of supply to the growing demand. Thus, prices do not change.

We have a quite different situation in the case of free-market economy simulations. The economy adjusts to exogenous shocks by both quantity and price movements. However, because the economy is in market-clearing equilibrium in the benchmark period, total endowments of labor and capital are used at full capacity already. This implies that there is no opportunity for a general increase in production and income. Price changes can only generate a redistribution of income and production over the different actors in the economy. In this process the exchange rate plays an important role. Because the increase in the government budget deficit elicits 
an additional inflow of foreign capital, the exchange rate decreases and thus changes the terms of trade in favor of the home country.

The apparent effect of fixed factor supplies in the flexible price experiments is that government injections lead to levels of production that are lower than the levels that are realized in a fixed-price context. In Hungary, the export-oriented activities, such as agriculture as well as light and heavy industry, are performing much worse than under a fixed-price regime. Similar results are found for Poland. These results can be attributed to the large exchange-rate changes, which lead to a deterioration of the competitive position of domestic exporters.

While in Hungary under the flexible-price regime the production level of construction and services also lies below the level realized under a fixed-price regime, in Poland this is not always the case. Depending on the year and the type of government injection, the production level in construction and services can be higher in the flexible-price situation. This somewhat surprising effect is caused by the relatively strong linkage of these activities to investment and consumption and by the high levels of the categories of demand due to high institutional income levels.

This brings us to another interesting outcome, namely that the impact of government injections on household income is larger in a flexible-price economy than in a fixed-price economy. This is found in all experiments, both for Hungary and Poland. The reason for this is that in the flexible-price economy the impact of the increase in domestic prices resulting from the impossibility to increase domestic output is outweighed by the impact of the decrease in foreign prices resulting from the appreciation of the domestic currency.

Of course, both Poland and Hungary have recently reoriented themselves appreciably towards a market economy. The representation of these centrally planned economics by means of a fixed-price regime as in the SAM model is now losing relevance. Furthermore, an instantaneous shift of regimes from planning to market will bring with it changes in technology, returns, and so forth, which are not fully reflected in the specification of a CGE model based on current data. The CGE parameters are derived under the assumption that in the benchmark period the economy is a market economy that is in equilibrium. However, if the assumptions of the benchmark period do not hold, as is the case for an economy 
in transition, this means that parameters are misspecified. Consequently, the effects of simulated government measures, which depend on the model parameters, may not be interpreted as quantitative indicators of effects that will materialize when the economy has reached the stage of a free-market economy.

Under these circumstances, what is obtained under the SAM and CGE specification should be seen to represent the functioning of the economy under different rules of the game, and as such gives an insight into old and new mechanisms by which exogenous injections realize their quantity and price impacts.

\section{REFERENCES}

Bennett, J. (1989) The Economic Theory of Central Planning. Oxford: Blackwell.

Cohen, S.I. (1989) Multiplier Analysis in Social Accounting and Input-Output Frameworks. In Frontiers of Input-Output Analysis (R.E. Miller, K.R. Polenske, and A.Z. Rose, Eds.), Oxford: Oxford University Press, pp. 79-99.

Cohen, S.I. (1993) Patterns of Economic Restructuring for Eastern Europe, Aldershot, England: Avebury, Ashgate Publishing Ltd.

Dervis, K., de Melo, J., and Robinson, S. (1982) General Equilibrium Models for Development Policy. Cambridge: Cambridge University Press.

Piggott, J., and Whalley, J. (Eds.) (1985) New Developments in Applied General Equilibrium Analysis. Cambridge: Cambridge University Press.

Pyatt, G. (1991) Fundamentals of Social Accounting, Economic System Research 3:315341. 